\title{
Leitura da trama polifônica: apreensão minuciosa do funcionamento da língua
}

\author{
Reading of the polyphonic slot: minuting appearance of language operation
}

\author{
Andréia Inês Hanel Cerezoli \\ Universidade Federal da Fronteira Sul - UFFS - Chapecó - Santa Catarina - Brasil
}

Carla Roberta Sasset Zanette

Universidade de Caxias do Sul - UCS - Caxias do Sul - Rio Grande do Sul - Brasil

\begin{abstract}
Resumo: A leitura enunciativa exige a participação ativa do leitor na reconstrução do sentido do discurso e, na perspectiva da teoria da polifonia, pode ser sistematizada em dois níveis: (1) descrição das diferentes vozes presentes no discurso; e (2) identificação das atitudes do locutor frente estas vozes. Este estudo mostra como os diferentes pontos de vista são importantes para que o leitor compreenda proficientemente o discurso, suas combinações e instruções. A fundamentação teórica está alicerçada em Ducrot, na Semântica Argumentativa (SA) ou Teoria da Argumentação na Língua (TAL), Flores e Teixeira (2005), Azevedo (2016), Negroni (2005), entre outros. Aplica-se, nesta investigação, a metodologia proposta por Ducrot, que consiste na observação, descrição e explicação do sentido do discurso para chegar à significação na língua. A descrição polifônica do discurso permite explicar, por exemplo, a atualização de um conector, mesmo ausente graficamente. Cientes da necessidade de um número maior de observações, descrições e explicações polifônicas, fica o convite aos leitores para mergulharem na trama de vozes do discurso.
\end{abstract}

Palavras-chave: Leitura Enunciativa. Teoria da polifonia. Sentido. Vozes discursivas.

Abstract: The enunciative reading requires the active participation of the reader in the reconstruction of the senses of discourse and, in the perspective of the Polyphonic Theory of Enunciation, can be systematized in two levels: (1) description of the different voices present in the discourse; and (2) identification of the speaker's attitude towards these voices. This one the present study intends to show how polyphonic indications are important for the reader to understand the speech proficiently, its combinations and instructions. The theoretical foundation is based on Ducrot, creator and researcher of Argumentative Semantics or Theory of Argumentation in Language, to the present day, Flores and Teixeira, Azevedo, Negroni, among others. The methodology proposed by Ducrot, which consists of the observation, description and explanation of the meanings of the discourse to arrive at meaning in the language, is applied in this investigation. The polyphonic description of the speech allows to explain, for example, the update of a connector, even if it is not present in the graph. Aware of the need for a greater number of polyphonic descriptions, readers are invited to delve into the web of speeches and to be amazed by the revelations and polyphonic plots.

Keywords: Enunciative Reading. Polyphonic Theory. Sense. Discursive voices. 


\section{Introdução}

Ducrot persegue e descreve, há mais de trinta anos, uma trama, pouco evidente, mas muito envolvente e reveladora, uma trama linguística, a polifonia enunciativa. Partindo dos fundamentos teóricos apresentados por Ducrot acerca da teoria da polifonia, este artigo mostra como as indicações polifônicas são importantes para que o leitor compreenda proficientemente o discurso, suas combinações e instruções. Pretende-se observar, descrever e explicar o anúncio $^{1}$ dos serviços oferecidos por uma cartomante, buscando as diferentes vozes presentes, as instruções e as limitações aí impostas.

Como este trabalho insere-se em uma perspectiva enunciativa, em que o leitor participa ativamente da construção do sentido do discurso, a investigação justifica-se porque, ao se descrever e explicar fenômenos discursivos menos evidentes para um usuário de língua ${ }^{2}$ menos hábil, mas fundamentais para a reconstrução do sentido visado pelo locutor, contribui-se para uma leitura efetivamente proficiente $^{3}$. Na fundamentação teórica, alguns recortes foram definidos: o conceito de polifonia e o aporte teórico ficam circunscritos aos textos de Ducrot: Le mots du discours (1980); O dizer e o dito (1987) e Polifonia y Argumentation (1990). A perspectiva enunciativa fundamenta-se, principalmente, em Flores e Teixeira (2005). Já a abordagem da leitura em uma perspectiva enunciativa apresenta fundamentação em autores como Azevedo (2016a, 2016b), Teixeira (2005), entre outros.

Para alcançar o objetivo proposto, o trabalho está organizado em quatro grandes eixos teóricos: (1)

1 Embora o anúncio seja apresentado em sua totalidade a análise não se refere ao todo do anúncio, pelo espaço deste trabalho.

2 Adotando a distinção estabelecida para diferenciar os usuários do sistema linguístico, entende-se por usuário de língua aquele que faz da língua um instrumento para conferir sentidos às suas interações verbais, suprindo as demandas que a sociedade the coloca. (AZEVEDO, 2016a, p. 49)

3 Azevedo (2016a, p. 56) entende que uma leitura efetivamente proficiente é a leitura não limitada aos signos atualizados no discurso, mas a leitura que considera e compreende as combinações e as associações que estão na origem do que foi produzido. campo enunciativo; (2) nuances da leitura em uma perspectiva enunciativa; (3) Teoria da Argumentação da Língua; e (4) teoria da polifonia. O trabalho é complementado por um quinto eixo destinado à análise polifônica.

\section{Enunciação: singularidade e pluralidade}

Toda e qualquer investigação científica iniciase com a tomada de algumas decisões, as quais, como alerta Barbisan (2012), constituem-se como não ingênuas, mas epistemológicas, decorrentes de pontos de vista acerca da linguagem, da leitura etc. Assim, os objetivos desta seção são: (1) situar o campo de estudos enunciativos; e (2) apresentar alguns fundamentos da leitura em perspectiva enunciativa.

Buscar a homogeneidade de conceitos e perspectivas na ciência linguística revela-se uma empreitada quase sempre frustrante, devido à diversidade de métodos e objetos que a grande área abriga. Mesmo em um único campo é possível identificar diferentes conceitos e definições, o que exige que qualquer linguista situe os aportes teóricos que norteiam suas pesquisas. Assim, o termo linguística da enunciação é utilizado a partir de Flores e Teixeira $(2005)^{4}$, reconhecendo-se que não corresponde a um termo unânime entre todos os linguistas, mas bem fundamentado e promissor aos estudos linguísticos.

O campo da Linguística da Enunciação abriga diferentes teorias, o que justifica a ideia da pluralidade anunciada no subtítulo desta seção, voltadas a pesquisas linguísticas que buscam descrever, à sua maneira, as relações entre linguagem em uso e sujeito linguístico, dado que justifica a ideia de singularidade também apresentada no subtítulo. (FLORES; TEIXEIRA, 2005). Outra observação dos autores diz respeito ao fato de que a definição do campo da linguística da enunciação não

4 O livro Introdução à Linguística da Enunciação (FLORES; TEIXEIRA, 2005) reúne alguns artigos publicados anteriormente pelos autores citados, logo é comum encontrar referência a Flores (2001), quando se trata da apresentação da Linguística da Enunciação como um campo. 
tem o objetivo de homogeneizar diferentes perspectivas, mas mostrar pontos de contato entre as diferentes abordagens. Flores e Teixeira (2009), referindo os critérios apresentados no Dicionário de linguística da enunciação (FLORES et al., 2009), reafirmam quatro critérios para a inclusão de uma teoria ao campo enunciativo: (1) referência a Saussure; (2) análise da linguagem do ponto de vista do sentido; (3) elaboração explícita de uma teoria sobre o tema da enunciação; e (4) presença da subjetividade nos estudos da linguagem. Esses critérios serão explorados de maneira ilustrativa a partir da TAL.

Algumas considerações sobre 0 campo enunciativo. Primeiramente, "[...] a enunciação não é um nível de análise linguística, mas um ponto de vista." (FLORES; TEIXEIRA, 2005, p. 109-110), quer dizer, um princípio epistemológico que explica, por exemplo, que as teorias enunciativas voltam-se para a compreensão do aspecto semântico da língua e, mesmo que outros níveis (sintático, fonológico etc.) possam servir de objeto de pesquisa, a finalidade será sempre explicar o sentido, "[...] sentido essencialmente determinado pela subjetividade no discurso." (TEIXEIRA, 2005, p. 198), sempre circunstancial, logo, irrepetível. Ou, nas palavras de Flores et al. (2011, p. 41), "Constitui um fato enunciativo de linguagem todo fenômeno que servir para explicitar a maneira pela qual o sujeito se marca naquilo que diz.", quer dizer, os dêiticos de pessoa, tempo e espaço, mas, também, os recursos linguísticos de opinião, qualificação, gradualidade etc., como afirmam Negroni e Tordesillas Colado (2001, p. 71)

Explicitadas tais particularidades, na sequência, apresentam-se algumas implicações da compreensão da leitura como fenômeno enunciativo.

\subsection{Leitura enunciativa: complexidade e envolvimento}

O desafio do trabalho com leitura surge não só das motivações científicas da pesquisa acadêmica mas, principalmente, das angústias enfrentadas na prática docente das pesquisadoras. É na atuação docente no cotidiano escolar, seja na Educação Básica, seja no Ensino Superior, que se constatam as dificuldades da grande maioria dos usuários de língua em compreender os discursos orais ou escritos de uso cotidiano. Dificuldades potencializadas no trabalho com discursos científicos. Logo, aliar a investigação científica às aflições pedagógicas enfrentadas, parece uma importante contribuição do linguista ${ }^{5}$ aos usuários de língua.

Antes da apresentação de alguns fundamentos acerca da leitura enunciativa, é apropriado justificar o subtítulo que define o tema deste tópico "complexidade e envolvimento". O termo "complexidade" refere uma das condições que devem ser consideradas na pesquisa que toma como objeto a leitura. Teixeira (2005, p. 195), alerta que "[...] é preciso considerar que a leitura é um fenômeno complexo que não se esgota em um só modo de olhar.", quer dizer, não importa sob qual abordagem teórica o fenômeno da leitura é concebido, analisado, descrito ou explicado, nunca será possível dar conta de todas as suas sutilezas, logo, reafirma-se que nenhuma perspectiva teórica se sobrepõe às demais, apenas "olha" seu objeto a partir de alguns pressupostos e com objetivos diferentes. Já o segundo termo "envolvimento" refere-se a uma das condições impostas aos linguistas que decidem desbravar o universo enunciativo, porque o sentido não está "pronto" no discurso, é preciso construí-lo, perseguindo as indicações presentes e pressupostas na enunciação. Isso porque, como sintetiza Bréal, no seu texto Essai de Semantique (1897, p. 182), "[...] as observações das quais se ocupa o semanticista [aquele que estuda o sentido] se ocultam um pouco mais ao olhar."

É chegada a hora de conceituar ou, minimamente, fundamentar o conceito leitura enunciativa. Alguns pontos fundamentais à concepção enunciativa de leitura: (1) a leitura não é uma atividade passiva; (2) "o sentido tem uma dupla

\footnotetext{
5 Para Azevedo (2016a, 49) o linguista transforma o sistema linguístico em objeto de estudo, define abordagens epistemológicas, teóricas e metodológicas para descrever e explicar esse sistema, sua constituição e atualização, quer dizer, é aquele que propõe teorias para esclarecer os diferentes níveis de análise linguística e/ou o uso deste sistema.
} 
dimensão: a do sentido dado pela estrutura da língua, reiterável, e a do sentido dado pela enunciação, sempre mutável e adaptável, porque o sujeito aí está implicado." (TEIXEIRA, 2005, p. 200); (3) o sentido não é dado a priori; (4) o sentido não se encerra no texto, mas é produzido de forma ativa por aquele que lê; e (5) há mais de um sentido para um discurso, mas não qualquer sentido. A exemplificação dos fundamentos ilustra, brevemente, tais implicações no processo de leitura enunciativa.

O primeiro ponto "a leitura não é uma atividade passiva" representa o trabalho do leitor proficiente, que não se limita a decodificar, mas se esforça para perceber como o locutor se marca naquele discurso. Em (1) infelizmente, houve reprovações! o leitor precisa "ler" muito mais que uma informação ou constatação, também perceber que há um desabafo, uma decepção, uma surpresa etc. Além disso, precisa constatar quais são as continuações possíveis para esse enunciado e aquelas que o discurso impede.

O segundo ponto "o sentido tem uma dupla dimensão: a do sentido dado pela estrutura da língua, reiterável, e a do sentido dado pela enunciação, sempre mutável e adaptável, porque o sujeito aí está implicado.", pode ser ilustrado com um exemplo já conhecido. Um promotor que durante uma acusação enuncia (2) senhores, senhores ... dirigindo-se aos jurados. Embora atualize o mesmo signo da língua (repetível) não produz o mesmo sentido, já que na segunda atualização é produzido um sentido de "apelo", por exemplo.

Já o terceiro aspecto "o sentido não é dado a priori" pode ser verificado em situações enunciativas como (3) a mesa está servida, que não contém apenas uma afirmação, mas, também, um convite para sentar-se à mesa e desfrutar da refeição, ou uma ameaça etc.

Por sua vez, o quarto ponto, no qual "o sentido não se encerra no texto, mas é produzido de forma ativa por aquele que lê", indica que, em (4) a menina abriu os olhos, é preciso que o leitor "leia" nessa informação que, num momento anterior ao relatado, os olhos da menina estavam fechados, por exemplo, encontra-se pressuposta linguisticamente a impossibilidade de abrir algo que antes não se encontrava fechado.

O último tópico "há mais de um sentido para um discurso, mas não qualquer sentido" pode ser exemplificado a partir de (5) é tarde!, que pode assumir o sentido do tempo que traz (É tarde, o filme começou), no caso, o início do filme, ou do tempo que leva (É tarde, o menino cresceu), referindo-se à infância, mas, dificilmente, um sentido de lugar.

As indicações anteriores podem ser sintetizadas com as palavras de Azevedo (2016b, 75, grifo da autora) "Entendo por leitura o processo interativo do sujeito com o discurso escrito, com o propósito de constituir sentido no que está sendo lido." Nesse contexto, processo interativo deve ser entendido não só como uma atividade do leitor ao discurso, mas a busca das indicações, postas e pressupostas, no discurso para a reconstituição do sentido. Outra característica desse processo interativo, que a autora define como leitura, é ser composto por três níveis ordenados e hierarquicamente dispostos: a) decodificação; b) compreensão; e c) interpretação. O primeiro consiste na decifração do código, reconhecimento e combinação de letras, palavras e enunciados. Consolidadas essas ações, é possível passar ao segundo nível, quando o leitor constitui, de modo analítico $^{6}$ e sintético ${ }^{7}$, o sentido das inter-relações das unidades e da totalidade semântica enunciativa do discurso. Decomposto em partes e recomposto em unidade, o leitor passa ao último nível, quando estabelece relações entre o conteúdo temático e outros contextos de produção e recepção. (AZEVEDO, 2016b, p. 75-76).

Dessa forma, Azevedo (2016b) reafirma e amplia uma perspectiva já apresentada por Teixeira e Ferreira (2008) de que a compreensão enunciativa de leitura transcende a concepção do processo de construção do significado que se encerra com a decifração do código

6 A compreensão analítica consiste na decomposição da totalidade do discurso em partes (enunciados, palavras), com o intuito de examinar cada uma das partes e das relações entre estas.

7 A compreensão sintética consiste na recomposição do discurso, observadas as inter-relações semânticas previamente compreendidas por análise. 
[...] o sentido das palavras não se resolve numa análise de elementos linguísticos vistos isoladamente, mas circula pelo enunciado, influenciando e deixando-se influenciar, pois as palavras não encerram um sentido só seu, mas significam nas inter-relações que se dão no processo de sintagmatização, em solidariedade com outras palavras. (TEIXEIRA; FERREIRA, 2008, p. 68).

A próxima seção apresentará a teoria eleita como fundamentação da abordagem do discurso selecionado: a Teoria da Argumentação na Língua.

\section{Teoria da argumentação na língua: oposição e identificação}

A Teoria da Argumentação na Língua (TAL) foi criada na França por Oswald Ducrot e colaboradores, ainda na década de 60 , e é desenvolvida até os dias atuais. Apresenta várias fases em seu desenvolvimento, sempre almejando maior coerência com os princípios saussurianos. Esta seção tem como objetivo: (1) mostrar o distanciamento da TAL a outras perspectivas teóricas; e (2) identificá-la ao campo da linguística da enunciação, objetivos que justificam o subtítulo dessa seção.

Oswald Ducrot procura esclarecer, ao longo de suas obras, não apenas os postulados da TAL mas, também, mostrar a quais concepções a Teoria está se opondo. Ducrot (1990) afirma que a teoria foi desenvolvida em oposição às concepções: (1) tradicional do sentido; 2) tradicional da argumentação; e 3) da unicidade do sujeito falante.

Ducrot (1990) entende a concepção tradicional do sentido como a divisão do sentido em denotação e conotação. A denotação, circunscrita às indicações objetivas, assinalando a representação da realidade. A conotação englobando as indicações subjetivas e intersubjetivas. Ao passo que aquelas mostram a atitude do locutor frente à realidade, essas se referem às relações do locutor com seus interlocutores. Opondo-se a essa concepção ${ }^{8}$, a TAL suprime essa separação porque, de acordo com seu criador,

Não acredito que a linguagem ordinária

8 Alguns pesquisadores classificam a TAL como não referencialista (GARCÍA NEGRONI; LESCANO, 2005), não representacionalista (GARCÍA NEGRONI; COLADO, 2001), não descritivista ou não veritativa. possua uma parte objetiva ou tampouco acredito que os enunciados da linguagem deem acesso direto à realidade; em todo caso, eles não a descrevem diretamente. Em minha opinião, se a linguagem ordinária a descreve, a faz através dos aspectos subjetivos e intersubjetivos. O modo como a linguagem ordinária descreve a realidade consiste em torná-la objeto de um debate entre os indivíduos. (DUCROT, 1990, p. 50, tradução das autoras). ${ }^{9}$

Segundo a concepção tradicional de argumentação, um discurso contém argumentação quando cumpre três requisitos: (1) o discurso deve conter dois segmentos A (argumento) e C (conclusão). " $A$ ordem em que $A$ e $C$ são apresentados é indiferente [... $]^{10}$ (DUCROT, 1990, p. 72, tradução das autoras); (2) A (argumento) indica um fato $H$, podendo ser julgado como verdadeiro ou como falso independentemente de $\mathrm{C}$ (conclusão) "[...] A tem um valor de verdade em si mesmo, mesmo que a conclusão imaginada pelo falante não seja conhecida. $^{11}$ (DUCROT, 1990, p. 73, tradução das autoras); 3) a conclusão C pode ser inferida a partir do fato $H$ "[...] a língua desempenha um papel muito pequeno na argumentação."12 (DUCROT, 1990, p. 75, tradução das autoras). Ducrot avalia que, segundo a concepção tradicional, a relação entre H (fato) e C (conclusão) não é determinada pela língua, dependendo da lógica, da psicologia, ou do conhecimento de mundo, consistindo em uma argumentação essencialmente exterior à língua. No entanto, para o linguista "[...] a argumentação está marcada na própria língua."13 (DUCROT, 1990, p. 80, tradução das autoras)

A terceira concepção a que a TAL se opõe defende que por trás de cada enunciado há uma e somente uma pessoa que fala. Para elucidar seu pensamento, Ducrot mostra que "[...] em um mesmo

9 No creo que a lenguage ordinario posea una parte objetiva ni tampouco creo que los enunciados del lenguaje den acceso directo a realidad; em todo caso no la describen directamente. A mi modo de ver, si el lenguaje ordinario la describe, lo hace por intermedio de los aspectos subjetivo e intersubjetivo. La manera como el lenguage ordinario describe la realidad consiste em hacer de ella el tema de un debate entre los indivíduos.

$10 \mathrm{El}$ orden em el que se presenta $\mathrm{A}$ y $\mathrm{C}$ es indiferente [...]

11 A posee un valor verdad em sí mismo, aun si no se conoce la conclusión imaginada por el locutor."

12 [...] a lengua desempeña un papel muy reducido em la argumentación.

13 [...] la argumentación está marcada em la lengua misma. 
enunciado estão presentes vários sujeitos com status linguísticos diferentes."14 (DUCROT, 1990, p. 16, tradução das autoras), um dos fundamentos que sustentam a teoria da polifonia.

\subsection{Teoria polifônica da enunciação: vozes e sentidos}

É chegada a hora de esclarecer a vinculação da teoria da polifonia ao universo enunciativo, retomando-se os quatro critérios de Flores e Teixeira (2009) para a inclusão de uma teoria ao campo enunciativo.

Quanto ao primeiro critério: propor uma teoria com referência ao pensamento saussuriano. Ducrot (2006) declara que foi a leitura do Curso de linguística geral (CLG), especialmente o capítulo sobre valor, que o levou às pesquisas linguísticas. A contribuição deste trabalho encontra-se em mostrar como Ducrot inspira-se em Saussure, não apenas do ponto de vista da coerência dos conceitos elaborados, mas, principalmente, na questão metodológica da TAL. A investigação reafirma o pensamento de Dosse (1993, p. 67), que, na obra História do Estruturalismo, v.1: 0 campo do signo, ao discutir acerca do chamado "corte saussuriano", compartilha da ideia apresentada por Gadet "A abordagem descritivista, a prevalência do sistema, a preocupação em remontar até as unidades elementares a partir de procedimentos construídos e explícitos, é a nova orientação, oferecida por Saussure [..]" fundamentos encontrados na TAL, explicitados na sequência.

Mais algumas considerações se fazem necessárias. Saussure e Ducrot observam a linguagem a partir de objetivos diferentes. Enquanto 0 primeiro funda uma ciência que estuda 0 funcionamento da linguagem, a linguística; o segundo propõe uma teoria semântica estruturalista que permite observar, descrever e explicar a constituição do sentido do discurso para chegar à significação inscrita na materialidade linguística. Assim, por um lado, é possível que se estabeleçam algumas aproximações, mas, por outro, é um equívoco que se

$14[\ldots]$ em un mismo enunciado hay presentes vários sujetos com status linguísticos diferentes. insistam em algumas comparações.

Para fundar a ciência linguística, Saussure precisou definir o seu objeto, uma vez que se interrogando, declarou:

Será que a linguística encontra diante de si, como objeto primeiro e imediato, um objeto dado, um conjunto de coisas evidentes, como é o caso da física, da química, da botânica, da astronomia, etc,?

De maneira alguma e em momento algum: ela se situa no extremo oposto das ciências que podem partir do dado dos sentidos. (SAUSSURE, 2004, p. 23, grifo do autor)

E, justificando não ser possível abordar a linguagem, por se tratar de um objeto complexo, pois "Quem se coloca diante do objeto complexo que é a linguagem, para fazer seu estudo, abordará necessariamente esse objeto por tal ou tal lado, que jamais será toda a linguagem [...]" (SAUSSURE, 2004, p. 25), o linguista indica uma das dificuldades impostas à investigação linguística: abordar um objeto cujo dado não está revelado previamente.

No Curso de linguística geral (CLG), encontrase a explicação daquilo que o genebrino entende como cada um dos lados que compõem a linguagem "[...] a linguagem apresenta um lado individual e um lado social, sendo impossível conceber um sem ou outro." (SAUSSURE, 2006, p. 16, grifo das autoras). O primeiro correspondendo à fala (parole), individual, o segundo à língua (langue), social. Como é conhecido, Saussure toma, metodologicamente, como objeto da ciência linguística a língua, por entendê-la como um todo em si e um princípio de classificação e afirma "Com o separar a língua da fala, separa-se ao mesmo tempo: 1., o que é social do que é individual; 2.; o que é essencial do que é acessório e mais ou menos acidental." (SAUSSURE, 2006, p, 22). A língua é social e essencial porque o sistema existe virtualmente nos cérebros de um conjunto de indivíduos, sendo passível de repetição; já a fala é individual, acessória ou acidental porque cada indivíduo atualiza o sistema de uma maneira, nova a cada uso (irrepetível), não interferindo no sistema, por exemplo, variedades de pronúncia.

Saussure (2006, p. 23) define a língua como um "[...] sistema de signos onde, de essencial, só existe a união do sentido e da imagem acústica, e 
onde as duas partes do signo são igualmente psíquicas." Sendo a leitura de Saussure complexa, algumas observações: sistema precisa ser compreendido como um todo solidário, em que cada uma das partes depende da presença simultânea de outras partes. Além disso, o sistema não é estático, fixo ou imutável, ao contrário, é dinâmico. Signo representa a união de um conceito (significado) e uma imagem acústica (significante). A dinâmica do sistema é percebida já na sua própria constituição "[...] o conceito nos aparece como a contraparte da imagem auditiva no interior do signo, e, de outro, este mesmo signo, isto é, a relação que une seus dois elementos, é também, e de igual modo, a contraparte de outros signos da língua." (SAUSSURE, 2006, p. 133). A visão sistêmica dessa definição sintetiza o conceito central da ciência linguística saussuriana e da teoria semântica ducrotiana "[...] uma forma não significa, mas vale: esse é o ponto cardeal. Ela vale, por conseguinte ela implica a existência de outros valores. (SAUSSURE, 2004, p. 30, grifos do autor). O valor é definido então pelas relações estabelecidas em três níveis: 1) no interior do próprio signo, na relação do significado e do significante; 2) no discurso, em que os signos estabelecem relações baseadas no caráter linear da língua, nas relações sintagmáticas dos signos "Colocado num sintagma, um termo só adquire seu valor porque se opõe ao que o precede ou ao que o segue, ou a ambos." (SAUSSURE, 2006, p. 142); 3) na língua, associações mentais que não se limitam em aproximar signos que apresentam algo em comum, "[...] os termos de uma família associativa [relações associativas] não se apresentam nem em número definido nem numa ordem determinada." (SAUSSURE, 2006, p. 146).

Por óbvio, a ciência criada por Saussure é muito mais complexa e reveladora que essa rápida apresentação, mas a explicitação desses conceitos é representativa para sintetizar a filiação ducrotiana "Meu saussurianismo consistirá em admitir que o significado de um signo seja certo conjunto de relações entre signos." (DUCROT, 2006, p. 7). A metodologia eleita por Ducrot (1987, p. 52, grifo do autor) é o método da simulação "[...] o que nós tomamos por dado, por objeto de observação, é a maneira pela qual os enunciados [...] são interpretados nas situações particulares em que são empregados.". As duas citações apresentam conceitos importantes para compreender o objetivo da semântica argumentativa. Coerentemente com a ciência proposta por Saussure, a TAL opõe ${ }^{15}$ dois níveis: (1) a materialidade linguística; e (2) a realização linguística. O material linguístico "[...] é uma espécie de entidade abstrata, idêntica através dos seus empregos." (DUCROT, 1984. p. 368) o que corresponde a língua saussuriana. Enquanto a realização linguística corresponde a fala saussuriana " [...] aquilo que foi efectivamente pronunciado ou escrito." (DUCROT, 1984. p. 369). Ducrot (1984), em perfeita sintonia com a noção de valor saussuriano afirma:

Quando se diz que os valores correspondem a conceitos, subentende-se que são puramente diferenciais, definidos não positivamente por seu conteúdo, mas negativamente por suas relações com os outros termos do sistema. Sua característica mais exata é ser o que os outros não são.(SAUSSURE, 2006, p. 136)

Visualizando a TAL como um sistema, Ducrot define, no nível da abstração os conceitos: a) frase: material linguístico disponível ao locutor, no nível elementar, e b) texto: sequência de frases, no nível complexo. Já no nível da realização conceitua: a) enunciado: corresponde à realização da frase e, b) discurso: corresponde à realização do texto. O semanticista parte, então, do sentido do enunciado ou do discurso, para chegar à significação da frase ou do texto. Qualquer semelhança não é mera coincidência, mas filiação, já que Saussure parte da descrição da fala para chegar à explicação da língua para a consolidação de uma ciência linguística. Para Ducrot, o linguista semanticista deve observar, descrever e explicar como o sentido dos enunciados pode, por dedução, explicitar a significação da frase, entendida como um conjunto de instruções já previsto no sistema linguístico.

O que fundamenta esta nova perspectiva é a

15 Oposição constitutiva, não é possível conceber um sem o outro. 
observação de que uma descrição da palavra em si mesma dificilmente permitirá compreender a contribuição que ela fornece ao valor semântico global dos enunciados dos quais ela participa: não se vê com facilidade como reconstituir o sentido [significação] da frase a partir da significação das palavras, se esta última é considerada como um todo em si que não faz referência à sua introdução possível em enunciados. (DUCROT, 1987, p. 46).

O segundo critério: analisar a linguagem do ponto de vista do sentido, parece já ter sido contemplado na explicação anterior, quando se mostrou que Ducrot parte do sentido para chegar à significação.

Nesta nova perspectiva, a descrição de uma palavra [...] não é fazer correspondência desta palavra a uma certa noção; é antes fazer a indicação de uma regra que permita prever - ou mesmo, idealmente, calcular - o efeito desta palavra nos discursos em que é empregada. (DUCROT, 1987, p. 46)

Cabe, no entanto, ressaltar que Ducrot (2018, p. 15) afirma, dada sua filiação saussuriana, que descrever o sentido "[...] não tem explicação fora do próprio sentido, ou, em todo caso, [é] recusar-se a procurar sua explicação fora do próprio sentido." Assim, a TAL observa, descreve e explica o sentido considerando apenas o intralinguístico.

No terceiro critério: elaborar explicitamente uma teoria sobre o tema da enunciação, é preciso lembrar que Ducrot (1984) conceitua enunciação como o acontecimento histórico que está na origem de um enunciado, ainda no início do desenvolvimento da TAL e o mantém até os dias atuais, sem alterações. A definição de enunciação pelo semanticista permite afirmar que " [...] a mesma frase [repetível] deu lugar a diversos enunciados, mas nunca poderemos afirmar que alguém repetiu várias vezes o mesmo enunciado [irrepetível]". (DUCROT, 1984. p. 369), justamente porque a enunciação é sempre outra, não se trata do mesmo tempo, embora se possa tratar do mesmo espaço físico e do mesmo locutor. A enunciação é concebida como um acontecimento histórico e o sentido, produto dessa enunciação. No Dicionário de linguística da enunciação, a Nota Explicativa do termo enunciação apresenta

Ducrot constrói uma teoria do sentido, considerando-o um produto da enunciação. Por isso, sua noção de enunciação não se vincula ao ato, mas ao fato de que um enunciado aparece. Desse modo, não se interessa pelo sujeito produtor do enunciado, mas pelas figuras enunciativas constituídas no sentido do enunciado. Esse sentido traz uma representação da enunciação como um confronto de pontos de vista diferentes. Sendo assim, é a descrição do sentido do enunciado que evidencia a sua enunciação. (FLORES et al, 2009, p. 104, grifo das autoras)

A enunciação no âmbito da TAL não é propriamente o objeto de estudo, mas o fato reconstruído do surgimento histórico do enunciado.

Já o último critério: contemplar a presença da subjetividade nos estudos da linguagem, pode ser explicado de diferentes maneiras, nos diferentes momentos da TAL. Na teoria da polifonia, objeto deste estudo, a subjetividade é evidenciada não só na descrição dos diferentes pontos de vista presentes no enunciado, mas na explicação do ponto de vista assumido pelo locutor. Subjetividade observada, descrita e explicada sempre no nível intralinguístico.

Situando-se a filiação da TAL ao campo da enunciação, muitos dos fundamentos da teoria da polifonia já foram apresentados, mas precisam ser explicitados.

Historicamente, a teoria da polifonia surge no momento da TAL, definido como "forma recente" com a Teoria dos Topoi, mas, ao contrário da última, não foi abandonada, continua sendo estudada e desenvolvida por diferentes semanticistas. Linguisticamente, a teoria da polifonia inova ao mostrar que em um enunciado estão presentes vários personagens com status linguísticos diferentes e o sentido "[...] nasce do confronto desses diferentes sujeitos: o sentido do enunciado não é mais que o resultado das diferentes vozes que ali aparecem." ${ }^{\text {16 }}$ (DUCROT, 1990, p. 16, tradução das autoras). Os personagens: 1) sujeito empírico (SE): é autor efetivo do enunciado, o produtor do enunciado. Não é objeto da descrição semântica, pois é externo ao enunciado "[...] o linguista semanticista deve preocupar-se com o sentido do enunciado, quer dizer, deve descrever o

16 [...] nace de la confrontación de esos diferentes sujetos: el sentido del enunciado no es más que el resultado de las diferentes vocês que allí aparecen." 
que disse o enunciado, o que este traz." ${ }^{17}$ (DUCROT, 1990, p. 17, tradução das autoras); 2) locutor (L): ficção discursiva a quem se atribui a responsabilidade da enunciação no enunciado mesmo "[...] a pessoa apresentada como responsável pelo enunciado."18 (DUCROT, 1990, p. 66, tradução das autoras); e 3) enunciador $(E)$ : ficção discursiva, origem dos diferentes pontos de vista que se apresentam no enunciado "[...] o enunciador não é o suposto responsável pelos pontos de vista apresentados no enunciado."19 (DUCROT, 1990, p. 66, tradução das autoras).

Para chegar ao sentido, o sematicista deve: 1) apresentar os pontos de vista dos diferentes enunciadores; e 2) indicar a posição do locutor em relação aos pontos de vista identificados. O locutor pode adotar três tipos de atitudes: a) "El locutor puede em primer lugar identificarse com uno de los enunciadores como es el caso de la aserción." (DUCROT, 1990, p. 66, grifo das autoras), o locutor identifica-se com 0 enunciador, quando sua enunciação tem como objetivo impor o ponto de vista apresentado por este.; 2) dar a aprovação a um enunciador " [...] el locutor indica que está de acuerdo con ese enunciador aun si el enunciado no tiene como objetivo hacer admitir el punto de vista de ese enunciador." (DUCROT, 1990, p. 66); e 3) opor-se a este enunciador "[...] es decir la de rechazar su punto de vista." (DUCROT, 1990, p. 67)

Uma simples descrição semântica para explicar os conceitos anteriores e anunciar alguns elementos da análise seguinte.

\section{(6) o jogador não renovou o contrato}

O enunciado em questão revela, no mínimo, duas situações polifônicas: a) negação; e b) pressuposição. Quanto à primeira situação, Ducrot descreve que todo o enunciado negativo consiste em um diálogo cristalizado de dois enunciadores: um

17 [...] el linguista semanticista debe preocuparse por el sentido del enunciado, es decir debe describir lo que dice el enunciado, lo que éste aporta."

18 [...] la persona presentada como responsable del enunciado."

19 [...] el enunciador no es ni el presunto responsable de los puntos de vista presentados em el enunciado." enunciador que afirma que o jogador renovou 0 contrato; e um segundo enunciador que afirma que 0 jogador não renovou o contrato. O locutor rejeita o ponto de vista do primeiro enunciador e assume o ponto de vista do segundo enunciador. A outra situação polifônica elucida pontos de vista a partir do termo renovou. Um enunciador afirma que já havia um contrato; outro ponto de vista é apresentado por um segundo enunciador que indica que um novo contrato foi oficializado; e um terceiro ponto de vista sustenta que o contrato já existente teve condições novas.

A descrição polifônica de renovou indica que o locutor aceita os pontos de vista apresentados pelo primeiro e pelo segundo enunciador, mas assume o ponto de vista apresentado pelo terceiro enunciador. Diversas pesquisas observam, descrevem e explicam outros fenômenos polifônicos, mas este estudo fica restrito a estes: (1) negação; e (2) pressuposição.

\section{Análise: negação e pressuposição}

Como fora anunciado na introdução, este tópico pretende realizar a análise polifônica do anúncio dos trabalhos de uma cartomante. $\mathrm{O}$ anúncio foi obtido de forma aleatória no site de busca Google $^{20}$. A análise não pretende esgotar a apresentação de todas as situações polifônicas ou descrever todo o anúncio, devido aos limites de um trabalho como este, mas mostrar como o diálogo polifônico precisa ser revelado para que se possa chegar ao sentido do discurso. Supondo-se essa uma das contribuições deste trabalho ao campo da leitura enunciativa, uma vez que, como afirma Ducrot (1980, p. 15) "[...] o valor semântico de uma frase argumentativa contém, entre outras coisas, um conjunto de instruções relativas a estratégia a seguir para decodificar [compreender] seus enunciados.", quer dizer, qualificar o leitor para que esse possa conferir sentido às suas interações verbais, atendendo as exigências que a sociedade lhe coloca. O fragmento que será aqui analisado está

20 Não será apresentado na íntegra, devido as limitações de espaço de um trabalho como este. 
indicado na parte superior do anúncio (7) não diga nada Ihe direi tudo!

Inicialmente, é preciso citar uma importante característica da língua, a gradualidade ${ }^{21}$. Observa-se que (7) relaciona os dois extremos de uma escala gradual 1) nada; e 2) tudo. O primeiro indicando a absoluta ausência de algo e o segundo, no extremo oposto da escala, a absoluta presença.

Dado que reforça a presença de um importante indicador de subjetividade, pois, como afirma Negroni e Colado (2001, p.71), "[...] texto é suscetível de manifestar subjetividade [...] por meio de recursos linguísticos de opinião, de qualificação, de gradualidade, [...] procedimentos que, por sua vez, se realizam no discurso mediante o emprego de caracteres tipográficos, pontuação [...]". Como o locutor pretende impor ao leitor a credibilidade dos trabalhos prestados, busca impressioná-lo, não só pela atualização (colocar em ato) da relação dos dois extremos da escala gradual mas, também, pela atualização do ponto de exclamação.

Em (7.1) não diga nada pela descrição polifônica da negação estão presentes um primeiro enunciador que ordena diga nada e um segundo enunciador que ordena não diga nada. A sentido de ordem é interior ao discurso pela atualização do modo imperativo, quer dizer, decorre das relações interdiscursivas. Outra contribuição desta pesquisa é materializar a ideia ducrotiana "[...] desejaríamos mostrar, numa última observação, que ela [a negação] não diz respeito apenas à negação explícita, a que é expressa pelo morfema não, mas também à negação implícita incorporada nos subentendidos ou pressupostos dos enunciados não diretamente negativos." (DUCROT, 1981, p. 199).

Dado que ajuda a descrever e explicar a trama polifônica em (7.1) que exige uma descrição ainda mais minuciosa, pois, segundo a compreensão destas pesquisadoras, tem-se aqui uma dupla presença de negação: (1) atualizada em não; e (2) atualizada em nada. A presença dessa dupla negação,

21 A gradualidade é uma relação semântica estabelecida entre palavras, no âmbito do sistema linguístico, a qual fornece ou enfraquece argumentativamente as expressões assim relacionadas. (AZEVEDO, 2015, p. 81) frequentemente, pode ser compreendida como uma afirmação, já prevista no sistema em enunciados como (8) não diga não em que o locutor espera do alocutário sim; ou (9) nadica de nada de açúcar em que o locutor reitera a ausência nadica de nada para afirmar a presença de uma pouca quantidade de açúcar.

Supondo-se que tal descrição seja aceitável, (7.1) ainda apresenta outro enunciador, um ponto de vista que ordena diga, exatamente o enunciador assumido pelo locutor. A atualização deste ponto de vista pode ser complementada com a descrição e a explicação pela pressuposição.

Quanto à pressuposição, Ducrot (1987, p. 30, grifo das autoras) afirma que

[...] a repartição do conteúdo dos enunciados em elementos semânticos postos - cuja responsabilidade é endossada pelo locutor -e em elementos semânticos pressupostos cuja responsabilidade o locutor partilha com o ouvinte - detém, antes de mais nada, uma função polêmica. Quando se tenta definir a pressuposição que, [...], não responde a nenhuma necessidade lógica, é-se levado a considerar que ela possibilita aprisionar o ouvinte em universo intelectual que ele não escolheu, mas que lhe é apresentado como coextensivo ao próprio diálogo.

Observa-se que diga pressupõe não só a ordem, atualizada pelo imperativo, mas o apelo à informação, uma vez que dizer, é dizer algo. Apelo que não existiria em um enunciador que apresentasse como ponto de vista cala-te! Supondo-se que tal descrição seja aceitável, está pressuposto em dizer, dar alguma informação.

Já em (7.2) Ihe direi tudo três pontos de vista são afirmados: um primeiro eu direi; um segundo eu direi a você e um terceiro eu direi tudo a você. $\mathrm{O}$ locutor aceita os pontos de vista apresentados pelo primeiro e pelo segundo e assume o ponto de vista do terceiro enunciador.

Até aqui a observação, descrição e explicação da trama de vozes que levam a constituição do sentido do discurso, confirmam a ideia de Ducrot (1980, p. 11, tradução das autoras) "[...] o que é importante para a compreensão de um texto [discurso], são não somente as indicações que ele traz, ao destinatário, mas também as manobras às 
quais ele o obriga, os caminhos que ele o faz seguir.", bem como justifica o título deste trabalho que indica que a leitura da trama polifônica permite a apreensão minuciosa do funcionamento da língua.

Descritos e explicados os dois enunciados relacionados em (7), é preciso, ainda, desenlaçar e explicar como o locutor relaciona (7.1) e (7.2): não diga nada the direi tudo. Supondo-se aceita a existência de uma relação atualizada pelo locutor entre (7.1) e (7.2), embora ausente graficamente, é preciso explicar como o locutor, considerando os pontos de vista assumidos em (7.1) e (7.2) posicionase, pela atualização desta relação implícita, frente a um novo ponto de vista.

Supondo-se, mais uma vez, aceita a descrição anterior, esclarece-se a ausência gráfica do elo que une (7.1 diga) e (7.2 eu direi tudo a você) em (7). A ausência gráfica do conector "encoberta" a ideia de concessão, sentido global de (7). O leitor proficiente, após ter identificado as diferentes tramas polifônicas, chegaria ao sentido parafraseado, por exemplo, $\left(7^{*}\right)$ se você me dizer algo, então Ihe direi tudo, uma ideia de concessão, pois como alerta Ducrot (1980, p. 12, tradução nossa) "[...] a compreensão do enunciado implica a descoberta da conclusão precisa [exata] visada pelo locutor."

\section{Considerações: convite e surpresas}

Esperamos, neste trabalho, ter mostrado: (1) o grande campo da Linguística da Enunciação, a pluralidade das teorias e um dos aspectos capazes de singularizar o campo, a relação entre linguagem em uso e sujeito linguístico; (2) a leitura em uma perspectiva enunciativa; demanda de um leitor ativo, capaz de perceber a dupla dimensão do sentido em oposição a inexistência de um sentido a priori; (4) a Teoria da Argumentação na Língua, uma teoria que se distancia da perspectiva representacionalista e da concepção de argumentação tradicional ao assumir o sentido como um jogo polifônico; (4) a teoria da polifonia como fundamento para descrever e explicar fenômenos inter e intralinguísticos como a negação e a pressuposição.
Além disso, supondo-se aceito que a leitura polifônica pode contribuir efetivamente para a construção do sentido e para o desenvolvimento da compreensão leitora, pois, como afirma Ducrot (1987, p. 40) "[...] no nível do enunciado, a pressuposição aparece como uma tática argumentativa dos interlocutores; ela é relativa à maneira pela qual eles se provocam, e pretendem impor-se uns aos outros, um certo modo de continuar o discurso.", o presente trabalho reafirma e explicita a ideia ducrotiana de que a pressuposição é uma tática argumentativa, já que impõe ao interlocutor instruções e limitações à continuidade do discurso ou a compreensão leitora proficiente.

Assim, encerra-se este trabalho com o convite para que os leitores deste artigo mergulhem na trama de vozes dos discursos e se surpreendam com as revelações e tramas polifônicas.

\section{Referências}

ANSCOBRE, Jean-Claude; DUCROT, Oswald. La Argumentación em la lengua. Editorial Gredos, S.A.: Madrid, 1994.

AZEVEDO, Tânia Maris de. Encadeamentos argumentativos, relações sintagmáticas e associativas: reflexão sobre o ensino da leitura. Antares, Caxias do Sul, v. 8, n. 15, p. 48-65, jan.jun. 2016a.

Polifonia linguística: uma proposta de transposição didática para o ensino de leitura. Letras de Hoje, Porto Alegre, v. 51, n.1, p. 73-81, jan.-mar. 2016b.

BARBISAN, Leci Borges. O sentido no discurso: o olhar da Teoria da Argumentação na Língua. In. DI FANTI, Maria da Glória; BARBISAN, Leci Borges. (Org.) Enunciação e Discurso: tramas e sentidos. São Paulo: Contexto, 2012.

BRÉAL, Michel. Ensaio de Semântica: ciência das significações. São Paulo: EDUC, 1992.

DOSSE, François. História do estruturalismo, v.1: o campo do signo, 1945 - 1966. São Paulo: Ensaio; Campinas, SP: Editora da Universidade Estadual de Campinas, 1993.

DUCROT, Oswald. Polifonía y argumentación conferencias del seminario Teoría de la Argumentación y Análisis del Discurso. Cali: Universidad del Valle, 1990. 
Enciclopedia EINAUDI. Lisboa: Imprensa Nacional, Casa da Moeda, 1984.

La Sémantique Argumentative peut-elle se réclamer de Saussure? In. SAUSSURE, Louis de (Org.) Nouveaux regards sur Saussure. Genebra: Librairie Droz S.A., 2006.

O dizer e dito. Campinas SP: Pontes, 1987.

Os Riscos do Discurso: Encontros co Oswald Ducrot. São Carlos: Pedro \& João editores, 2018.

FLORES, Valdir do Nascimento et al. Enunciação e gramática. 2. ed. São Paulo: Contexto, 2011.

. Dicionário de linguística da enunciação. São Paulo: Contexto, 2009.

FLORES, Valdir do Nascimento; TEIXEIRA, Marlene. Introdução à linguística da enunciação. São Paulo: Contexto, 2005.

Bakhtiniana, São Paulo, v.1, n. 2, p. 143164, jul.-dez. 2009.

NEGRONI, María Marta García; TORDESILLAS COLADO, Marta. La enunciación em la lengua: de la deixis a la polifonia. Madrid: Editorial Gredos, S.A., 2001.
NEGRONI, María Marta García; LESCANO, Alfredo M. Prólogo. In. CAREL, Marion; DUCROT, Oswald. La Semántica argumentativa: una introducción a la teoría de los bloques semánticos. 1.ed. Buenos Aires: Colihue, 2005.

SAUSSURE, Ferdinand de. Escritos de Linguística Geral. São Paulo: Cultrix, 2004.

Curso de linguística geral. 27. ed. São Paulo: Cultrix, 2006.

TEIXEIRA, Marlene. É possível a leitura? Revista Nonada: Porto Alegre, ano 8, n.8, 2005, p. 195204.

\section{COMO CITAR ESSE ARTIGO}

HANEL CEREZOLI, Andréia Inês; SASSET ZANETTE, Carla Roberta. Leitura da trama polifônica: apreensão minuciosa do funcionamento da língua. Signo, Santa Cruz do Sul, v. 44, n. 80, p. 132-143, jul. 2019. ISSN 19822014. Disponível em: <https://online.unisc.br/seer/index.php/signo/article/view/13065>. Acesso em: doi: https://doi.org/10.17058/signo.v44i80.13065. 